\title{
Elevated soluble Flt1 mediates an anti-angiogenic state in patients with ANCA-associated vasculitis
}

\author{
S Le Roux ${ }^{1,2,3+}$, R Pepper $^{4+}$, A Dufay $^{2}$, M Néel $^{1,2,3}$, N Lamandé $^{5}$, M Rimbert ${ }^{1,6}$, R Josien ${ }^{1,3,6}$, M Hamidou $^{3,7}$, \\ M Hourmant ${ }^{1,2,3}$, H T Cook ${ }^{8}$, B Charreau ${ }^{1,2,3}$, E Larger $^{5}$, A Salama ${ }^{4^{*}}$, F Fakhouri $^{1,2,3^{*}}$ \\ From 5th European Workshop on Immune-Mediated Inflammatory Diseases \\ Sitges-Barcelona, Spain. 1-3 December 2010
}

\section{Introduction}

Anti-neutrophil cytoplasm antibody-associated vasculitidies (AAV) represent a group of necrotizing small vessel vasculitidies that include Wegener's granulomatosis, microscopic polyangiitis and Churg-Strauss-Syndrome. To date, little is known regarding endothelial cell survival and vessel regeneration in patients with AAV, despite the increasingly recognised role of vascular endothelial growth factor (VEGF) in mediating vessel repair.

\section{Aim}

Assess the role of sFlt1 in patients with AAV.

\section{Material and methods}

Were included 40 patients with PR3-AAV during active disease $(n=20)$ or remission $(n=20)$ and 23 patients with MPO-AAV during active disease $(\mathrm{n}=10)$ or remission $(\mathrm{n}=13)$. Eighteen additional PR3-AAV patients had paired serum samples drawn at the onset of the disease and at three months of follow-up.

\section{Results}

Serum levels of soluble Flt1 (sFlt1), a potent inhibitor of VEGF, are significantly increased during the acute phase of PR3-AAV $(2592 \pm 11347 \mathrm{pg} / \mathrm{ml})$ and MPO-AAV (476 $\pm 4258 \mathrm{pg} / \mathrm{ml})$ compared to controls $(118 \pm 269 \mathrm{pg} / \mathrm{ml})$. sFlt1 levels decreased during disease remission but remained increased compared to controls in patients with PR3-AAV. sFlt1 serum levels correlated with serum levels of C5a, an anaphylatoxin released following complement activation. Serum from patients with acute
PR3-AAV induced the release of sFlt1 by human monocytes in vitro, but failed to induce a similar effect on endothelial cells. Pre-treatment of monocytes with an anti-C5a receptor blocking antibody attenuated sFlt1 release. Serum from patients with acute AAV induced a disruption of blood flow in the chicken chorioallantoic membrane assay and this effect was prevented by incubating patients' serum with an excess of human VEGF.

\section{Conclusion}

Our data indicate that a complement mediated-increase in sFlt1 occurs during acute AAV which leads to an "antiangiogenic" state that hinders endothelial repair. "Proangiogenic" therapies, which would include complement activation inhibitors, may enhance endothelial repair during AAV and thus reduce renal vascular scarring.

\section{Author details}

'INSERM UMR 643, Nantes, France. ${ }^{2} \mathrm{CHU}$ Nantes, Institute of Transplantation Urology Nephrology, Nephrology Dept., Nantes, France. ${ }^{3}$ Université de Nantes, Faculté de Médecine, Nantes, France. ${ }^{4}$ Centre for Nephrology, University College London, Royal Free Hospital, London, UK. ${ }^{5}$ INSERM 833, Collège de France, Paris, France. ${ }^{6} \mathrm{CHU}$ de Nantes, Immunology Laboratory, Nantes, France. ${ }^{7} \mathrm{CHU}$ de Nantes, Internal medicine Dept., Nantes, France.

${ }^{8}$ Centre for Complement and Inflammation Research, Imperial College, London, UK.

Published: 25 November 2010 